\title{
Andreas Riem. Ein Europäer aus der Pfalz. Schriften der Siebenpfeifer-Stiftung
}

Jean Delinière

\section{(2) OpenEdition \\ 1 Journals}

\section{Édition électronique}

URL : https://journals.openedition.org/ahrf/1048

DOI : 10.4000/ahrf.1048

ISSN : 1952-403X

Éditeur :

Armand Colin, Société des études robespierristes

\section{Édition imprimée}

Date de publication : 1 mars 2001

Pagination : 132

ISSN : 0003-4436

\section{Référence électronique}

Jean Delinière, « Andreas Riem. Ein Europäer aus der Pfalz. Schriften der Siebenpfeifer-Stiftung »,

Annales historiques de la Révolution française [En ligne], 323 | janvier-mars 2001, mis en ligne le 21 avri 2004, consulté le 23 avril 2022. URL : http://journals.openedition.org/ahrf/1048 ; DOI : https://doi.org/ 10.4000/ahrf.1048

Ce document a été généré automatiquement le 23 avril 2022.

Tous droits réservés 


\title{
Andreas Riem. Ein Europäer aus der Pfalz. Schriften der Siebenpfeifer-Stiftung
}

\author{
Jean Delinière
}

\section{RÉFÉRENCE}

Karl H.L. Welker (Hg.), Andreas Riem. Ein Europäer aus der Pfalz. Schriften der

Siebenpfeifer-Stiftung, Bd. 6, Stuttgart, Jan Thorbecke Verlag, 1999, 242 p.

1 Cet ouvrage collectif, résultat d'un colloque tenu à Frankenthal dans le Palatinat, a paru à l'occasion du 250e anniversaire de la naissance d'Andreas Riem, un jacobin allemand qui serait complètement oublié aujourd'hui, si Walter Grab n'avait pas souligné l'importance de cet auteur parmi les admirateurs allemands de la Révolution française. Cette étude a le grand mérite de montrer sans concession la biographie et l'œuvre très variée de cet Aufklärer berlinois. Né en 1749 à Frankenthal, il a fait des études de théologie à Heidelberg et exercé, entre autres, à partir de 1775, des fonctions de pasteur en Prusse où il finira comme secrétaire de l'Académie des arts et des sciences mécaniques, avant d'être banni de cet État en 1795 en raison de ses écrits politiques. Il séjournera peu après auprès de Jourdan, à Cassel, puis dans différents pays d'Europe, en Hollande, en Angleterre, plusieurs fois à Paris avant de retourner dans son Palatinat natal où il achèvera sa vie, dans la misère, en 1814. Son œuvre assez considérable est composée aussi bien d'écrits philosophiques que théologiques, de romans, de récits de voyages ou d'articles politiques, voire de conseils adressés à des ministres prussiens ou aux participants du Congrès de Rastatt. Partout, on retrouve les mêmes constantes: Aufklärer convaincu, il prêche une «religion naturelle» épurée de tout dogme, une tolérance qui le poussera à demander, en 1798, l'égalité des droits pour les Juifs d'Allemagne; admirateur inconditionnel de Frédéric II, il n'a de cesse de reprocher à ses successeurs de s'écarter des grands principes politiques et philosophiques de leur illustre prédécesseur; fervent admirateur de la Révolution française qui a donné aux 
citoyens la liberté et l'égalité, il approuve l'instauration de la République, se détourne de la Terreur qu'il dénonce comme une nouvelle tyrannie, mais fonde ses espoirs dans le Directoire pour restaurer la République; par contre, il reste convaincu qu'une révolution est impossible dans l'Allemagne morcelée de son temps et que les réformes ne pourront venir que d'en haut de la part de souverains éclairés qui comprendront qu'il est urgent d'agir s'ils veulent conserver leurs trônes; à la place des Habsbourg, il verrait d'ailleurs volontiers un roi de Prusse sur le trône impérial d'une Allemagne réorganisée et débarrassée de ses principautés ecclésiastiques rétrogrades; enfin, il tient à écarter d'une nouvelle Europe aussi bien la Grande-Bretagne, cette vile puissance purement mercantile que cet État «asiatique» qu'est la Russie à ses yeux.

2 Chacun de ces aspects de son œuvre est étudié en détail dans treize exposés clairs et précis et cet ouvrage est complété par un index détaillé des bibliothèques où l'on peut trouver encore les différents textes publiés par Andreas Riem. On ne peut donc que saluer ce livre qui marque une première approche scientifique de cet ardent défenseur de la liberté. 